2019-01-01

\title{
Microplastics in the Environment
}

\section{Thompson, Richard}

http://hdl.handle.net/10026.1/13644

10.1039/9781788013314-00060

Royal Society of Chemistry

All content in PEARL is protected by copyright law. Author manuscripts are made available in accordance with publisher policies. Please cite only the published version using the details provided on the item record or document. In the absence of an open licence (e.g. Creative Commons), permissions for further reuse of content should be sought from the publisher or author. 
Disclaimer

'This is a copy of the accepted paper as submitted for publication. Readers are advised to refer to the final version of the paper which can be found at

https://pubs.rsc.org/en/Content/Chapter/9781788013314-00060/978-1-78801-331-4

\section{Abstract}

Microplastics are small pieces of plastic debris $<5 \mathrm{~mm}$ in diameter. These particles have accumulated in the environment as a consequence of: the direct release of small particles; such as those used in cosmetics; or as a consequence of wear, for example fibres released from textiles. The main source of microplastic is considered to be the fragmentation of larger items of plastics in the environment. Microplastics are widely distributed in freshwater and marine environments including remote locations such as the arctic and deep sea. A wide range of organisms are known to ingest microplastics and laboratory studies indicate the potential for harmful effects. Plastic debris can also transport co-contaminants including chemical additives and pollutants sorbed from sea water. These chemicals can be released to organisms upon ingestion, but there is little evidence that plastics provide an important pathway leading to toxicological effects in environmentally relevant scenarios. Removing microplastics form the environment is impractical and the most effective solutions are to minimise the release of plastics to the environment as litter. In this regard much could be achieved by actions to reduce the accumulation of larger items of litter such as packaging which will eventually fragment into microplastics. 


\title{
5 Microplastics in the environment
}

\section{Issues in Environmental Science \& Technology, Volume 46}

Plastics and the Environment

\author{
Professor Richard C. Thompson and Imogen E. Napper
}

Marine Biology and Ecology Research Centre, School of Biological and Marine Sciences, University of Plymouth, Drake Circus, Plymouth, PL4 8AA, UK

Email: R.C.Thompson@plymouth.ac.uk 
Table of contents

5.1 Introduction

5.2 Size Classifications of Plastics

5.3 Sources of Microplastics

5.4 Distribution and Abundance

5.5 Impacts

5.7 Solutions

5.8 Conclusions

5.9 References 


\subsection{Introduction}

In order to understand the sources, consequences and accumulation of microplastics in the environment it is important to first set microplastics into context within the wider topic of marine litter and in particular plastic litter. Plastics are synthetic polymers that can be made into a vast range of inexpensive, lightweight and durable products that bring numerous societal benefits (Thompson et al. 2009b). There are many variants, with the most common plastics including polyethylene (PE), polypropylene (PP), polyvinyl chloride (PVC), polyethylene terephthalate (PET) and polystyrene (PS). The versatility of plastics has resulted in an exponential increase in global demand, from around 5 million tonnes in the 1950s to over 300 million tonnes today (Plastics Europe 2015).

Some applications of plastics have a long service life, such as PVC and PP components in vehicles or the construction industry. However, around $40 \%$ of all the plastic produced is used for packaging, which is predominantly single use (Plastics Europe 2015). These items are frequently made of highly durable polymers such as PE or PET (Barnes et al. 2009). As a consequence end of life plastic items are now a major component of waste in managed systems and substantial quantities are accumulating as litter in the environment (Jambeck et al. 2015). It is important to recognise that numerous types of material have been reported as litter but the vast majority is plastic; accounting for around $70 \%$ of the litter collected in beach cleans the most abundant items being, single-use plastic packaging, together with rope and netting (Nelms et al. 2017). Plastic litter has been identified as a major global 
problem by the United Nations Environment Assembly and in the G7 Leader's declaration 2015 (GESAMP 2016, Werner et al. 2016).

Plastic debris has been reported across a wide range of sizes from discarded fishing nets that can be 1000s of meters in length to microscopic fragments just microns in diameter. This paper will focus on microplastic which is widely defined as being pieces less than $5 \mathrm{~mm}$ in diameter (Arthur et al. 2009, Galgani et al. 2010). Microplastics accumulate from primary and secondary sources. The distinction between the two is based on whether the particles were originally manufactured within the microplastic size range (primary) or whether they have resulted from the fragmentation of larger items (secondary).

While the term microplastic was first used to describe microscopic fragments of plastic in 2004 (Thompson et al. 2004) piece s in the currently defied microplastic size range have been reported since the 1970s and it is apparent that microplastic are a ubiquitous component of anthropogenic debris in marine and freshwater environments (Carpenter et al. 1972, Browne et al. 2011, Eriksen et al. 2013, Eerkes-Medrano et al. 2015, Lebreton et al. 2017). Microplastics greatly outnumber large plastic items in marine systems, but only account for a small proportion of the total mass of plastic in the ocean (Browne et al. 2010, Cozar et al. 2014). This means that even if we were able to stop the discharge of macroplastic litter into the sea today, on-going degradation of the larger litter items already at sea and on beaches would likely result in a sustained increase in microplastics for many years to come. Additionally, with an ever-increasing reliance on plastic products, their use and disposal will continue, which in the absence of improved waste management will 
further increase the accumulation of microplastic (Law and Thompson 2014, Thompson 2015).

Once in the marine environment, microplastic cannot be cost-effectively detected, collected for recycling or successfully removed (Andrady 2017). It also presents a range of negative economic and environmental consequences (Werner et al. 2016). This review will consider the definition of microplastics, describe the sources, distribution patterns and subsequent impacts in the marine environment. We will also discuss potential solutions to reduce further accumulation of microplastics; focussing product design, waste management, recyclability, education, policy and behaviour change.

\subsection{Size Classifications of Plastic}

Plastic debris can be defined and described in a variety of ways including by origin (e.g. from the land, fishing-related or sewage-related debris) size, shape, colour, polymer type or original usage. One of the commonly used calcifications is according to size. Plastic can enter the aquatic environment in a wide range of sizes and has been reported from 1000s of meters in length to microns in diameter (Cole et al. 2011, Hidalgo-Ruz et al. 2012). Three categories that are widely used to describe the size of plastic contamination; macroplastic (>20 mm diameter), mesoplastic (5$20 \mathrm{~mm}$ ) and microplastic $(<5 \mathrm{~mm}$ ) (Thompson et al. 2009a, MSFD GES Technical Subgroup on Marine Litter 2011). However, it is important to note that there are no 
universal conventions on nomenclature and this challenges inter-comparability of data.

The accumulation of macroplastic has been reported in a wide range of habitats (Ryan et al. 2009, Browne et al. 2015a, Eerkes-Medrano et al. 2015). Due to its high visibility, contamination of the environment by macroplastic may be perceived as one of the most concerning forms of plastic pollution. Clean-up campaigns typically focus on these larger items and there is wide geographical variability in abundance, which increases the difficulty of analyzing potential trends. Items of macroplastic debris are often sufficiently recognisable to be categorised according to their original usage; for example, packaging, fishing or sewage related debris. Attributing sources of microplastics is more challenging.

While the upper bound of microplastics is reasonably consistently taken to be particles less than $5 \mathrm{~mm}$ the lower bound is often set by operational constraints. For example, in field studies it is the mesh size of nets used to sample surface water (Law et al. 2010) or the sieves used in sampling beach sand (Hidalgo-Ruz et al. 2012) that primarily determine the lower-size limit of sampled microplastics. Particles as small as a few microns in diameter have been separated form an environmental matrix and identified as plastic using spectroscopy; it seems likely that even smaller nanoplastic particles also occur in the environment, but it is not currently feasible to separate and identify plastic particles of this size from complex environmental mixtures (GESAMP 2016, Koelmans et al. 2016).

[ Figure 1 near here] 


\subsection{Sources of Microplastics}

Microplastics can result from the direct release of small particles $(<5 \mathrm{~mm}$ in diameter). Such particles are described as primary microplastics, for example microbeads which are used in some cosmetics (Napper et al. 2015, Figure 1a), They can also be formed form the fragmentation of the larger plastic items once they have entered the environment and these are described as secondary microplastics (Figure 1b).

There are a wide range of potential sources and pathways that result in the accumulation of plastic in the marine environment. Much of the litter in aquatic environments enters as macroplastic from land-based actions such as general littering, dumping of waste and loss during waste collection as well as that from inappropriately managed landfill sites (Duis and Coors 2016). Plastic waste is collected, and then contained in a waste management framework which is designed to help minimize loss to the environment. From these land-based sources, plastic litter then has the potential to end up in municipal wastewater and freshwater systems (e.g. from windblown litter escaping) which can then potentially emit to the oceans from coastlines or rivers (Cole et al. 2011, Jambeck et al. 2015, Schmidt et al. 2017). In industrialized countries, waste that is deposited in landfills is usually covered regularly with soil or a synthetic material, and the landfill is cordoned by a fence to prevent any debris accidentally leaving. However, in developing regions this is often not the case (Barnes et al. 2009, Jambeck et al. 2015). 
It has been estimated that on a global scale, the input of plastic into the oceans from land based sources is in the region of 6.4 million tons per annum. Furthermore, assuming there are no improvements in waste management infrastructure, the cumulative quantity of plastic waste available to enter the marine environment from land could increase by approximately three times over the next decade (Jambeck et al. 2015) (Figure 2).

[Figure 2 near here]

In addition, quantities of plastic are released from marine based sources such as shipping, aquaculture and commercial fishing (Andrady 2017, GoScience 2017). Studies have indicated a significant relationship between the number of ocean-based plastic items found on beaches and the level of commercial fishing activity (Ribic et al. 2010) Unintentional loss of in-service macroplastic products can also occur when catastrophic events, such as tsunamis(Lebreton and Borrero 2013, Kamachi et al. 2016), hurricanes, or floods, carry large amounts of material of all kinds into the marine environment (Thompson et al. 2005, Law et al. 2010, GESAMP 2016).

The main source of microplastics in the environment is typically regarded as the fragmentation of these larger items of plastic debris; resulting in secondary microplastics (Cole et al. 2011, Law and Thompson 2014, GESAMP 2015). This degradation occurs as a consequence of ultra-violet (UV) radiation and oxidation, which overtime can reduce the structural integrity of the plastic, resulting in fragmentation. This can be facilitated by physical forces from abrasion, wave-action 
and turbulence (Barnes et al. 2009, Andrady 2017). Depending on the chemistry of the polymer, bulk morphology and where it is exposed at, microplastics degrade at different rates in the marine environment (Gregory and Andrady 2003, Andrady 2011). However, fragmentation rates of plastic are largely unknown, and as a result little quantitative information is available on the relative contribution of secondary microplastics overall (Koelmans et al. 2014, Law and Thompson 2014). Given the large amount of macroplastics entering the environment, it is generally assumed that most microplastics have arisen from the fragmentation of larger items, continuously becoming smaller and smaller (GESAMP 2015).

Secondary microplastic can also be generated as a consequence of items such as tyres and textiles becoming abraded during life in service. Subsequently, it is clear that substantial quantities of fibres have accumulated in the environment (Lusher et al. 2013, Woodall et al. 2014, Dris et al. 2015). For example; the washing of clothes made from synthetic materials is a direct secondary microplastic source. These microplastic fibers are released from a garment during a washing cycle and then can enter the environment via wastewater. Some fabrics release fibers more readily than others; research by Napper and Thompson (2016) reported that a wash load of $6 \mathrm{~kg}$ of acrylic clothing could release over 700,000 fibers.

Primary microplastics enter the marine environment in a variety of different ways as particles that are already within the microplastic size range. These particles are produced through extrusion or grinding, either as a feed stock for manufacture of larger products or for direct use (Barnes et al. 2009); for example in cleaning products (Cole et al. 2011), cosmetics (Fig.1a) (Zitko and Hanlon 1991, Napper et al. 
2015) and as air-blasting media (Barnes et al. 2009). Compared to secondary microplastics, production volumes can be used to provide estimates of potential inputs to the environment. Some uses such as in cosmetic products is now beginning to be regulated (Napper et al. 2015, Anderson et al. 2016).

Plastic microbeads from facial scrubs are an example of primary microplastics used in cosmetics. After their intended use, these microbeads are likely to enter household wastewater and some will escape the waste water treatment system into the environment (Browne et al. 2011, van Wezel et al. 2016). It has been estimated that 94,500 microbeads could be released from an defoliant in a single use, and this was estimated to translate to the UK alone emitting 16-86 tonnes $\mathrm{yr}^{-1}$ (Napper and Thompson 2016). Other potentially important sources are from microplastic used in medicines, drilling fluids for oil /gas exploration and in industrial abrasives (i.e. for airblasting to remove paint from metal surfaces) (Derraik 2002, Barnes et al. 2009, Duis and Coors 2016).

While there has been much focus on the marine environment, a wide range of freshwater habitats are also contaminated with plastic, and rivers provide major pathways for plastics to the ocean (Dris et al. 2015, Eerkes-Medrano et al. 2015, GESAMP 2016). Microplastics have been detected at very high levels globally in rivers and lakes (Auta et al. 2017). Rivers can transport considerable quantities of plastic (micro - macro size) to the oceans and some of this debris can travel from locations far inland. The concentrations in various parts of a river reflect different sources such as waste water treatment plants, tributaries and weirs (Claessens et al. 2011, Klein et al. 2015, Mani et al. 2015). Substantial quantities of plastic including microbeads from 
cosmetics, sanitary related items and other particles can be carried to rivers or directly to the oceans with waste water.

For any plastic that enters waste water treatment, the efficiency of capture (i.e., before the effluent is discharged into the environment) depends on the particular treatment process. There is limited information on the efficiency of waste water treatment plants to capture plastic; particularly microplastic. However, some studies indicate extremely high capture rates (>95\%) of plastic particles (Murphy et al. 2016). Given the large volume of influent daily, even low loss rates could result in detectable concentrations of these plastic particles in the environment (Browne et al. 2011, Eriksen et al. 2013). Murphy et al. (2016) predicted that waste water treatment plants could release 65 million microplastic particles every day (Murphy et al. 2016). In the event of sewage overflow, wastewater and any plastic debris therein can also bypass treatment as a consequence. Even if microplastic is intercepted during wastewater treatment the resultant sewage sludge is often returned to the land as a fertilizer, hence plastic is still released to the environment. Most sources of microplastic are extremely difficult to trace back to their original source. For plastic pieces larger than around $20 \mu \mathrm{m}$, it is possible to identify what type of plastic polymer a particular piece of debris is made out of. For larger items of plastic debris it is often easier to identify the origin for; such as fishing gear and sewage-related debris (Nelms et al. 2017).

Trends of production, consumer-use and demographics all point to a further increase of in the use of plastic in the future (Auta et al. 2017, Geyer et al. 2017). Hence, there are considerable concerns that the problems of plastic pollution will escalate unless disposal practices change. Despite difficulties in identifying specific sources 
of microplastic sized fragments, ooverall the sources of marine plastic litter are mostly well known; however there is a lack of knowledge concerning the relative importance of the different sources. Furthermore, due to the wide variety of sources and pathways, estimations for the amount of plastic in the environment are difficult to obtain and will require direct measurement of the input rates of plastic waste by wind, tidal and ocean wave transport. They will also require a consistent protocols for replicable measurement of measurement of waste generation, collection rates, classification and waste disposal methods for rural areas and urban centers in countries around the world (Geyer et al. 2017, Law and Annual 2017).

\subsection{Distribution and Abundance}

Plastic debris is found in many different sizes and can accumulate in the oceans (Thompson et al. 2004), estuaries (Browne et al. 2010, Browne et al. 2011)and even in remote locations such as in arctic ice (Obbard et al. 2014) Within these environments, microplastic has been reported at the sea surface (Cozar et al. 2014) suspended in the water column (Lattin et al. 2004) and in sediments, including those in the deep sea (Van Cauwenberghe et al. 2013, Woodall et al. 2014). Plastic has also been reported in freshwater environments although there are fewer studies than in the marine environment (Eriksen et al. 2013, Eerkes-Medrano et al. 2015, Mani et al. 2015).

The concentration of microplastics recorded is directly influenced by the sampling method used, which can vary significantly between studies. A study modelling 
mismanaged plastic waste discharged from the land estimated annual inputs to the ocean of 4.8-12.7 million tonnes of macroplastic items globally $(10,000-27,000$ tonnes in the UK) (Jambeck et al. 2015). An alternative approach used empirical counts of litter at sea to describe the abundance of specific types of litter in particular environmental compartments. For example, based on data collected from net tows, Cozar et al. estimated there were $7,000-35,000$ tonnes of small (approximately $25 \mathrm{~mm}$ or less) debris at the sea surface (Cozar et al. 2014), while van Sebille et al. estimate $93,000-236,000$ tonnes, equivalent to $15-51$ trillion small particles (van Sebille et al. 2015) and Eriksen et al. (2014) estimated there was 270,000 MT of floating plastic in the oceans. However, these estimates exclude microplastics that can pass through the plankton nets used to gather the data (Eriksen et al., 2014). Hence discrepancies between figures can arise from differences in the method of estimation. Different sampling matrices such as sediment or water column use different techniques and express the results in various units making inter-comparison difficult (Hidalgo-Ruz et al. 2012). A further approach is to estimate inputs of specific categories of litter. For example, based on daily UK usage, it was estimated that a specific type of product, facial scrubs, could lead to release of 86 tonnes of microbeads (Figure 2a) to the environment per annum (Napper et al. 2015).

There are considerable challenges in extrapolating from the very limited empirical data available to make predictions even about current patterns of spatial and temporal distribution of plastic litter and likely trends. Some of the best estimates available have uncertainty levels of over 100 fold (van Sebille et al. 2015). There is also a lack of temporal data on which to base future projections. Hence making reliable long-term future predictions is not feasible. However, assuming business as 
usual, Jambeck et al. (2015) predict a three-fold increase in the amount of plastics in the ocean between 2015 and 2025 (Fig.2).

Given the practical limitations in sampling such a diverse form of contamination, it may therefore be beneficial to link monitoring either to categories of litter where there is clear evidence of harm, or to assessing the efficacy of specific interventions. This could include monitoring the abundance of plastic items that have been to focus of specific policies reductions for example the quantity of plastic bags found in the environment as a consequence of the single-use bag tax or reductions in the abundance of plastic microbeads in sewage as a consequence of legislative measure to reduce the quantity of microbeads used in cosmetics. Whereas widespread quantification of all microplastics, while important to our understanding of encounter rate and possible hare is likely to provide a relatively blunt tool for monitoring change. Whatever approach is used it is essential to be explicit about the limitations of the given sampling strategy and the associated limitations of any extrapolations made in subsequent modelling studies.

Despite current uncertainties in estimating levels of contamination, it is clear is that plastics have only been mass produced since the 1950s and therefore current levels of contamination reflect fairly rapid accumulation rates over just a few decades. The scale of the problem ahead is illustrated when one considers that on a global scale a similar quantity of plastics are likely to be produced in the next eight years as were produced in the whole of the 20th century (estimates updated to present day, after Thompson et al. 2009a). At the same time, it is important to recognise that the accumulation of plastics in the ocean is largely avoidable. By comparison with many 
other current environmental challenges, the benefits resulting from the use of plastics are not directly linked to the emission of plastic debris to the environment or to degradation of the environment. Hence, in theory at least, it is possible for society to retain the benefits of plastic products and at the same time reduce the quantity of plastic litter entering the environment (Thompson 2015). Identification of the sources is important to gain an accurate assessment of the quantities of plastics and microplastics entering the ocean, to provide an indication of regional or local 'hot spots' of occurrence, and to determine the feasibility of introducing management measures to reduce these inputs (GESAMP 2015).

Estimating the distribution of microplastic based on secondary inputs is particularly difficult since it relies on accurate assessment of the distribution of macroplastics and the degradation process (which is also not well known). There is a lack of data comparing the abundance of macroplastics and microplastics at local scales. However, it is unlikely that the abundance of microplastic and macroplastics will be closely correlated as large and small objects will be influenced by environmental processes to differing degrees. For example, larger floating objects will be more prone to transport by winds than microplastics (Browne et al. 2010, Kukulka et al. 2012) and this is reflected in circulation models used to simulate the transport of micro- and macro-debris (Eriksen et al. 2014, van Sebille et al. 2015).

Attention is currently being directed within the EU (MSFD GES Technical Subgroup on Marine Litter 2011) to compare and harmonise monitoring protocols, including those used for microplastics, to allow greater inter-comparability among data, and this topic has recently been the focus of a workshop hosted by the Ministry of the 
Environment in Japan as part of G7. Harmonisation of monitoring will be a key step towards increasing the accuracy and inter-comparability of spatial and temporal estimates of plastic debris. However, it is important to acknowledge the heterogeneity of plastic litter and recognise there is no current method to assess the total microplastic burden within a sample, and hence the data obtained provide an index of the quantity of microplastic rather than an absolute value. There have been some recent advances that aid plastic separation via oxidation of natural organic material, visualisation by staining and automation of polymer identification (Frere et al. 2016, Erni-Cassola et al. 2017, Maes et al. 2017, Tagg et al. 2017).

Plastic debris has the potential to become widely dispersed and this will be influenced by the nature and location of the point of entry, as well as the subsequent complex interactions of physical, chemical and biological processes (e.g. wind and currents) (Ryan et al. 2009, Kukulka et al. 2012, Faure et al. 2015, Ryan 2015, Fazey and Ryan 2016b). At the water surface, smaller pieces of plastic present lower rise velocities, they are less susceptible to transport by windage and are more susceptible to vertical transport (Kukulka et al. 2012). Some polymers such as polyvinyl chloride (PVC), and polyethylene terephthalate (PET), are denser than water and are more likely to sink, while polyethylene (PE), polypropylene (PP) and polystyrene (PS) are more likely to float. However, like any other surface immersed in water plastic debris rapidly accumulates fouling from micro-organisms as well as sediment particles. Over time this increases their apparent density causing even some of the less dense polymers to sink (Zettler et al. 2013, Fazey and Ryan 2016a). Hence, the sea bed could be the most likely long-term place for the accumulation of plastic debris. Some of the limited data available on accumulation in 
the deep sea supports this hypothesis but more work is needed to roach firm conclusions (Galgani et al. 1995, Galgani et al. 2000, Woodall et al. 2014). In addition, to transport via water bodies there is growing evidence of the importance of aeolian transport which may be particularly relevant for very small particles such as microplastics escaping from uncovered landfills (Rillig 2012, Dris et al. 2015, Duis and Coors 2016), or the dispersal of particles formed by wear in service such as textile and tyre wear (Napper and Thompson 2016).

\subsection{Impacts}

There is a reasonably extensive evidence base relating to the harm caused by marine litter. This can have a range of negative impacts on maritime industries, commercial fisheries, and infrastructure. It has also been found to affect a wide range of marine organisms as a consequence of entanglement and ingestion (Derraik 2002, Gall and Thompson 2015, Kuhn et al. 2015); for example, it has been reported that over 700 species of marine organisms have been reported to encounter marine debris, the majority of these encounters are with plastic debris and around $10 \%$ of reports are for encounters with microplastics (Gall and Thompson 2015). Impacts within the environment caused by plastic vary according to the type and size of the debris, and can occur at different levels of biological organization in a wide range of habitats (Browne et al. 2015b). The impacts of meso- or macroplastics have been reviewed for numerous marine species; particularly mammals, birds or turtles (Laist 1997, Derraik 2002, Gall and Thompson 2015, Kuhn et al. 2015). Encounters between organisms and macroplastic litter can negatively affect individuals, and a substantial proportion 
of some populations; for example, over $40 \%$ of sperm whales beached on North Sea coasts had marine litter including, ropes, foils and packaging material found in their gastro-intestinal tract (Unger et al. 2016), while over $95 \%$ of the population of norther fulmars (Fulmar glacialis) may contain plastic litter in some European waters (Van Franeker et al. 2016). Even though the data on impacts form macroitems of plastic debris is relatively extensive scaling up evidence from impacts on individuals to population-level consequences is challenging, since it is almost impossible to isolate the effects of plastic debris. For example, most species of marine turtles are red-listed by the International Union for Conservation of Nature as being (critically) endangered and frequent ingestion of macroplastics undoubtedly contributes to population decline; however, its level of contribution, as well as those of the other factors, cannot be isolated (Werner et al. 2016).

The impact of meso- or macroplastic is more prominent by eye, therefore it is often subject to extensive scientific research and media coverage. The effects of microplastics has received less attention but is increasingly being reported and have a variety of implications within the marine environment (Fig.3) (Andrady 2011, Cole et al. 2011, Wright et al. 2013b, Law and Thompson 2014).

[Figure 3 about here]

Although the weight fraction of microplastics in plastic litter is relatively small, they are able to interact with a very wide variety of marine organisms, ranging from zooplankton to marine mammals (Cole et al. 2013, Cole et al. 2015, Gall and 
Thompson 2015) . There are also concerns about the potential for microplastics to transport of non-native species or to act as vectors for potentially harmful chemicals in the environment (Rochman and Browne 2013, Rochman et al. 2013, Zettler et al. 2013).

The potential for the ingestion of plastic debris is greater with pieces in the microplastic size range. Microplastics occupy the same size fraction as sediments and some planktonic organisms, they are therefore bioavailable to a wide range of organisms; including whales, fish, mussels, oysters, shrimps, copepods and lugworms (Cole et al. 2013, Lusher et al. 2013, Cole et al. 2015, Gall and Thompson 2015, Kuhn et al. 2015) . For example, a study in South West England showed that of 504 fish, from 10 species, and over one-third had microplastics in their digestive tract (Lusher et al. 2013). Ingestion can also depend on properties other than size including shape, density and colour. For instance, low-density (i.e. buoyant) microplastics are potentially more likely to be ingested by pelagic feeders and highdensity microplastics by benthic feeders. As size, colour, density and shape is likely influence whether microplastic gets ingested (Moser and Lee 1992, Cousin et al. 2015, Lavers and Bond 2016, Santos et al. 2016), it is difficult to make generic predictions about the subsequent risks of marine biota ingesting microplastics.

Organisms at lower trophic levels have been reported to ingest and accumulate microplastic particles (Thompson et al. 2004, Browne et al. 2008, Wright et al. 2013b), which can then transfer between trophic levels in the food-web (Watts et al. 2015). Additionally, with very small particles, including those in the nano-size range, 
there is the potential for uptake across cell membrane, but little is known about any associated impacts (GESAMP 2016, Koelmans et al. 2016).

Floating plastics can also transfer organisms between locations. For macroplastic debris this includes the transport of species of invertebrates (Gregory 2009), while microplastics have been implicated in the transfer of microorganisms (Kirstein et al. 2016). For example, microplastics collected in the surface waters of the North Atlantic were colonized by a variety of organisms including bacteria, cyanobacteria, diatoms, ciliates and radiolaria (Zettler et al. 2013). Since plastics have been reported to travel over long distances, they may contribute to the dispersal of nonnative species (Barnes 2002). However, the relative importance of plastics compared to other vectors, including natural floating debris such as logs, and transport via shipping, has yet to be established.

From a human health perspective, there is concern that plastic debris can support diverse microbial communities that are distinct from those found in seawater or on other floating objects. Hence the colonization, survival and transport of pathogens on polymers presents a potential risk to human health, but further investigation is needed to establish the importance of this (Keswani et al. 2016, Kirstein et al. 2016).

Microplastic ingestion can induce subtle effects on behavior and ecological interactions such as the ability to escape from predators or migrate. Fish and invertebrates are known to ingest microplastic, leading to physical effects that include physiological stress responses (Browne et al. 2013, Rochman et al. 2013, Wright et al. 2013a) Other experiments have also shown that ingestion can compromise the 
ability of planktonic organisms to feed (Cole et al. 2015) and the ability of marine worms (Wright et al. 2013a) and fish (Cedervall et al. 2012) to gain energy from their food.

Manipulative experiments have been used to isolate the effects of microplastics from other environmental stressors and there is evidence of impacts, including effects on reproductive output, which could have associated population-level consequences (Sussarellu et al. 2016). However, many of the laboratory studies demonstrating effects from microplastics have used concentrations higher than those currently found in the environment (Lenz et al. 2016). While these experiments inform our understanding of thresholds in relation to future levels of contamination, they do not provide clear evidence of current environmental consequences.

Microplastics could also cause consequences at higher levels of biological organisation, including assemblages of organisms and the ecosystem services they provide. Teasing out such effects is challenging, but localised field experiments using macroplastics indicate even a single plastic carrier bag causes smothering which can alter the relative abundance of sediment-dwelling organisms as well as the ecosystem services they provide (Green et al. 2015). Recent experiments in microcosms also point to the potential for assemblage-level effects of contamination with microplastics (Green 2016, Green et al. 2017).

There are also concern about the potential for plastics and in particular microplastics to facilitate the transfer of potentially harmful chemicals to organisms. Microplastics have a larger surface area to volume ratio than macroplastics and are therefore 
more susceptible to contamination by a co-contaminants such as persistent organic pollutants (POPs) and to some extent, metals (Holmes et al. 2012). Hydrophobic organic pollutants readily sorb onto plastics, and can accumulate at concentrations several orders of magnitude higher than in seawater (Mato et al. 2001, Teuten et al. 2009). Additive chemicals are also incorporated into plastic products at the time of manufacture. These chemicals are intentionally added during the manufacture or processing; for example, to enhance the plastics durability and corrosion resistance or act as stabilizers, plasticizers or flame retardants. Some additives such as plasticizers are used at high concentrations (10-50\%) to ensure the functionality of the product (Andrady and Neal 2009).

Therefore, there are concerns about the potential for microplastics to facilitate the transfer of chemicals to marine life directly as a consequence of ingestion or indirectly via release to waterbodies (Teuten et al. 2009, Bakir et al. 2014). For chemicals that have sorbed to plastics form water the rate of release from the plastic is considerably enhanced in the presence of gut surfactant chemicals and increases further with temperature; such that the rate of release would be greater in a warm rather than a cold blooded organism(Bakir et al. 2014) (figure 4). Chemical uptake into tissues is determined by equilibria and modelling estimates indicate that the sorbtion of chemicals to plastic is unlikely to offer a substantial additional pathway in the transfer of chemicals from water to biota (Koelmans et al. 2013, Bakir et al. 2016). One recent study modelled the potential for transfer of harmful chemicals from seawater to marine organisms by several types of microplastics and then considered the consequences if these organisms were subsequently eaten by 
humans. The simulations predicted that microplastics were not likely to be an important factor in the transport of chemicals from seawater (Bakir et al. 2016)

[Figure 4 a near here]

Ingestion of plastic containing additives may also result in the chemicals leaching from the plastic and being transferred to organism. Additive chemicals can be present in high concentrations (Bakir et al. 2016) and it is considered their release could provide an important pathway for chemical transfer to biota (Oehlmann et al. 2009, Tanaka et al. 2013). However, more work will be needed to establish the potential for transfer of chemical additives, incorporated in plastic items at the time of manufacture. For example a recent study in Korea demonstrated that potentially harmful flame retardants could be released from buoys used in an aquaculture facility, leading to elevated concentrations of flame retardants in the surrounding environment (Al-Odaini et al. 2015).

It has been suggested in some media reports that consumption of fin-fish and shellfish that are contaminated with microplastics, and potentially chemicals, might present a threat to human health. However, the quantities of microplastics in seafood are typically low. In addition, studies of contaminated fish describe microplastics in the gut and this is typically removed before consumption. Similarly, with shellfish there is typically a depuration period prior to consumption. For organisms eaten whole, including the gut, estimates for high annual consumption of mussels indicated 
potential for transfer of 11,000 microplastic particles to an individual consumer (Van Cauwenberghe and Janssen 2014). Even in this fairly atypical scenario there is no evidence to indicate that microplastic would be harmful. More work is needed to establish the potential health risks from microplastics. This would require an assessment of dietary exposure to microplastics via a range of foods (GESAMP 2016) as well as work to establish the potential consequences of such ingestion.

Subsequently, within the seafood industry there is concern that contamination by microplastic may have negative effects on consumer perceptions affecting marketability even if there is no particular evidence of a risk to human health (GESAMP 2015, 2016). Notably potential effects have already been reported in the media and used in NGO campaigns (e.g., surfrider foundation, Canada). Similar perceptual effects on marketability have been reported when stocks are identified as being contaminated with low-level radioactivity or microorganisms (Parsons et al. 2006). Hence the actual risk of adverse effects on humans can be considerably different from the perceived risk that will affect marketability.

It is likely that there are also a range of sub-lethal effects that have not yet been recognized. While further research is needed to fully understand the environmental risks presented by microplastics, it is considered that because these small particles are readily available to organisms via ingestion and can be mistaken for prey, that they are likely to present different types of hazards to larger items. Summarising across all of the evidence, the EU Marine Strategy Framework Directive (MSFD) expert group on marine litter recently concluded that plastics [including microplastics] present a "large scale and serious threat to the welfare of marine animals" (Werner et al. 2016). 
From a risk assessment perspective, more work is needed to model the probability as well as the severity of encounters. With macroplastic debris this has recently been done for encounters between turtles and abandoned fishing nets in waters to the north of Australia (Wilcox et al. 2013). However, the wider ability to construct models of this type is limited, not only by a lack of understanding about some of the specific types of harm caused by different types of plastic debris, but also a lack of detailed empirical data on the current distribution of plastic; this is especially true for microplastic distributions which are particularly troublesome to quantify.

\subsection{Solutions}

It is clear that substantial quantities of litter are entering aquatic habitats daily (Jambeck et al. 2015, Mani et al. 2015, Schmidt et al. 2017). A combination of ineffective waste capture and ineffective sewage treatment, together with product designs, that do not reflect end-of-life scenarios all contribute to the release of plastics to the environment. In this context, waste can be defined as something of little or no value and hence the problem may be exacerbated by the inexpensive nature of most plastics, which facilitates short-lived applications and can also present an obstacle to the viability of recycling. Therefore, it must be recognized that the accumulation of plastic in the oceans is actually a symptom of a wider more systemic problem of linear use of materials and the rapid accumulation of waste. Hence, the overarching solutions to the problem of marine litter lie on land(Thompson 2015). Even in the absence of complete information on distribution and impacts, it is clear 
that the key action must be to reduce the quantity of litter entering the oceans from the land.

The potential threats to aquatic ecosystems presented by plastic debris, particularly microplastic, has been identified as a major global conservation issue and a key priority for research (Sutherland et al. 2010, GESAMP 2015, 2016). To fully understand the sources and scale of this contamination would require an internationally coordinated effort with comparable sampling and microplastic extraction techniques, as well as standardized recording methodologies to map and evaluate distribution (Hidalgo-Ruz et al. 2012, Fisner et al. 2017).

There are some management strategies and policies in place to reduce plastic contamination (Thompson 2015, GESAMP 2016, Thomas et al. 2016). Banning microbeads in cosmetics is an example of such legislation (Xanthos and Walker 2017). However, based on the levels of concern and the scale of problems outlined in this chapter it would appear that the measures currently in place are insufficient. In some cases, there are difficulties associated with enforcement; for example, the regulation of dumping at sea (MARPOL) is extremely difficult to enforce. Even in economically developed countries with robust waste management infrastructure, there are unnecessary obstacles to recycling, including the lack of availability of collection points, contamination of recycling feedstock, and the limited marketability of some recycled material (Hopewell et al. 2009, Thompson 2015).

Benefits of citizen focused activities such as beach cleaning are well recognized for their educational value as well as in terms of the litter removed (Nelms et al. 2017). 
Annual clean-up operations are now organized in many countries (Barnes et al. 2009) and are often run by voluntary organizations(Nelms et al. 2017). They can remove substantial quantities of litter from beaches and the coastline. Volunteer involvement in two of the largest clean up schemes in the UK (Marine Conservation Society Beach Watch and Keep Scotland Beautiful National Spring Clean) has been estimated to provide a value of approximately $£ 119,500$ in term of cleaning, which suggests that the total cost of actions to remove marine litter is considerable.

Due to the size of microplastics and their abundance worldwide, their entire removal by clean-up is not feasible. Additionally, current rates of entry for litter into the marine environment far exceed the potential for removal by clean-up. Therefore, the main priority must be to focus on preventing litter entering the oceans in the first place and a better understanding of the behaviors that lead to littering, as well as those that lead to engagement in recycling (Pahl and Wyles 2017, Pahl et al. 2017). Most plastics are inherently recyclable, yet many single-use items are not compatible with recycling. A key challenge therefore is to ensure end-of-life disposal via recycling is appropriately considered at the design stage.

There are also some potential distractions to the key solutions; such as altering the carbon source used to make plastics by utilizing plant base carbon rather than fossil carbon from oil and gas. While this utilizes a renewable and hence a more sustainable carbon source, it will not reduce the generation of waste nor the accumulation of litter. Biodegradable plastics are another potential distraction; while products that have been designed to degrade rapidly may reduce the amount of highly visible macroscopic plastic waste, many of these items merely fragment 
compromising the potential for product re-use and accelerating the production of microplastic fragments (Defra 2010, Roy et al. 2011, Thompson 2015).

Biodegradable or compostable plastics only present a solution in very specific settings where the associated waste collection is specifically managed, provides conditions suitable for degradation and products are labelled accordingly to facilitate appropriate disposal (Thompson 2015).

Education, outreach and awareness are effective ways to promote change in limiting indiscriminate disposal. However, in the past, approaches to address marine litter have mostly focused on end-of-pipe measures; in order to develop long term sustainable solutions there needs to be education and change in behavior right along the supply chain and this could be facilitated by greater dialogue between the various stakeholders from design, through production and use, to disposal (GoScience 2017). In short what is needed is a much better stewardship so that the benefits of plastic can be realized without the accumulation of unnecessary waste in managed systems and in the environment.

\subsection{Conclusions}

Microplastics are small particulate contaminants that are widely distributed in the environment. These particles arise from a range of sources, they are persistent and accumulating. Microplastics have been reported form the sea surface to the deep sea and are ingested by a wide range of organisms. There is evidence that ingestion of microplastics can lead to harmful effects; these appear to be associated with the physical presence of microplastic rather than release of chemical co-contaminants. 
Measure to reduce microplastic contamination should focus on minimising direct

inputs of small particles such as microbeads used in cosmetics, but more importantly reducing the quantity of larger items of litter entering the environment since these are already widely recognised to cause negative consequences for economies and wildlife; in addition they will ultimately fragment into microplastics.

\subsection{References}

Al-Odaini, N. A., W. J. Shim, G. M. Han, M. Jang, and S. H. Hong. 2015. Enrichment of hexabromocyclododecanes in coastal sediments near aquaculture areas and a wastewater treatment plant in a semi-enclosed bay in South Korea. Science of the Total Environment 505:290-298.

Anderson, A. G., J. Grose, S. Pahl, R. C. Thompson, and K. Wyles. 2016. Microplastics in personal care products: Exploring perceptions of environmentalists, beauticians and students. Marine Pollution Bulletin 113:454-460.

Andrady, A. L. 2011. Microplastics in the marine environment. Marine Pollution Bulletin 62:1596-1605.

Andrady, A. L. 2017. The plastic in microplastics: A review. Marine Pollution Bulletin 119:12-22.

Andrady, A. L., and M. A. Neal. 2009. Applications and societal benefits of plastics. Philosophical transactions of the Royal Society B 364:1977-1984.

Arthur, C., J. Baker, and H. Bamford. 2009. Proceedings of the international research workshop on the occurrence, effects and fate of microplastic marine debris. September 9-11, 2008. NOAA Technical Memorandum NOS-OR\&R30.

Auta, H. S., C. U. Emenike, and S. H. Fauziah. 2017. Distribution and importance of microplastics in the marine environment: A review of the sources, fate, effects, and potential solutions. Environment International 102:165-176.

Bakir, A., I. A. O'Connor, S. J. Rowland, A. J. Hendriks, and R. C. Thompson. 2016. Relative importance of microplastics as a pathway for the transfer of hydrophobic organic chemicals to marine life. Environmental pollution (Barking, Essex : 1987) 219:56-65.

Bakir, A., S. J. Rowland, and R. C. Thompson. 2014. Enhanced desorption of persistent organic pollutants from microplastics under simulated physiological conditions. Environmental Pollution 185:16-23.

Barnes, D. K. A. 2002. Biodiversity - Invasions by marine life on plastic debris. Nature 416:808-809.

Barnes, D. K. A., F. Galgani, R. C. Thompson, and M. Barlaz. 2009. Accumulation and fragmentation of plastic debris in global environments. Philosophical transactions of the Royal Society B:1985-1998.

Browne, M. A., M. G. Chapman, R. C. Thompson, L. A. A. Zettler, J. Jambeck, and N. J. Mallos. 2015a. Spatial and Temporal Patterns of Stranded Intertidal Marine Debris: Is There a Picture of Global Change? Environmental Science \& Technology 49:70827094. 
Browne, M. A., P. Crump, S. J. Niven, E. Teuten, A. Tonkin, T. Galloway, and R. Thompson. 2011. Accumulation of Microplastic on Shorelines Woldwide: Sources and Sinks. Environmental Science \& Technology 45:9175-9179.

Browne, M. A., A. Dissanayake, T. S. Galloway, D. M. Lowe, and R. C. Thompson. 2008. Ingested microscopic plastic translocates to the circulatory system of the mussel, Mytilus edulis (L.) Environmental Science and Technology 42:5026-5031.

Browne, M. A., T. S. Galloway, and R. C. Thompson. 2010. Spatial Patterns of Plastic Debris along Estuarine Shorelines. Environmental Science \& Technology 44:3404-3409.

Browne, M. A., S. J. Niven, T. S. Galloway, S. J. Rowland, and R. C. Thompson. 2013. Microplastic Moves Pollutants and Additives to Worms, Reducing Functions Linked to Health and Biodiversity. Current Biology 23:2388-2392.

Browne, M. A., A. J. Underwood, M. G. Chapman, R. Williams, R. C. Thompson, and J. A. van Franeker. 2015b. Linking effects of anthropogenic debris to ecological impacts. Proceedings of the Royal Society B-Biological Sciences 282.

Carpenter, E. J., S. J. Anderson, G. R. Harvey, H. P. Miklas, and B. P. Bradford. 1972. Polystyrene spherules in coastal waters. Science 178:749-750.

Cedervall, T., L. A. Hansson, M. Lard, B. Frohm, and S. Linse. 2012. Food Chain Transport of Nanoparticles Affects Behaviour and Fat Metabolism in Fish. Plos One 7.

Claessens, M., S. De Meester, L. Van Landuyt, K. De Clerck, and C. R. Janssen. 2011. Occurrence and distribution of microplastics in marine sediments along the Belgian coast. Marine Pollution Bulletin 62:2199-2204.

Cole, M., P. Lindeque, E. Fileman, C. Halsband, and T. S. Galloway. 2015. The Impact of Polystyrene Microplastics on Feeding, Function and Fecundity in the Marine Copepod Calanus helgolandicus. Environmental Science \& Technology 49:11301137.

Cole, M., P. Lindeque, E. Fileman, C. Halsband, R. Goodhead, J. Moger, and T. S. Galloway. 2013. Microplastic Ingestion by Zooplankton. Environmental Science \& Technology 47:6646-6655.

Cole, M., P. Lindeque, C. Halsband, and T. S. Galloway. 2011. Microplastics as contaminants in the marine environment: A review. Marine Pollution Bulletin 62:2588-2597.

Cousin, H. R., H. J. Auman, R. Alderman, and P. Virtue. 2015. The frequency of ingested plastic debris and its effects on body condition of Short-tailed Shearwater (Puffinus tenuirostris) pre-fledging chicks in Tasmania, Australia. Emu 115:6-11.

Cozar, A., F. Echevarria, J. I. Gonzalez-Gordillo, X. Irigoien, B. Ubeda, S. Hernandez-Leon, A. T. Palma, S. Navarro, J. Garcia-de-Lomas, A. Ruiz, M. L. Fernandez-de-Puelles, and C. M. Duarte. 2014. Plastic debris in the open ocean. Proceedings of the National Academy of Sciences of the United States of America 111:10239-10244.

Defra. 2010. Assessing the Environmental Impacts of Oxo-degradable Plastics Across Their Life Cycle. London.

Derraik, J. G. B. 2002. The pollution of the marine environment by plastic debris: a review. Marine Pollution Bulletin 44:842-852.

Dris, R., J. Gasperi, V. Rocher, M. Saad, N. Renault, and B. Tassin. 2015. Microplastic contamination in an urban area: a case study in Greater Paris. Environmental Chemistry 12:592-599.

Duis, k., and A. Coors. 2016. Microplastics in the aquatic and terrestrial environment: sources (with a specific focus on personal care products), fate and effects. Environmental Sciences Europe 28:1-25. 
Eerkes-Medrano, D., R. C. Thompson, and D. C. Aldridge. 2015. Microplastics in freshwater systems: A review of the emerging threats, identification of knowledge gaps and prioritisation of research needs. Water Research 75:63-82.

Eriksen, M., L. C. M. Lebreton, H. S. Carson, M. Thiel, C. J. Moore, J. C. Borerro, F. Galgani, P. G. Ryan, and J. Reisser. 2014. Plastic Pollution in the World's Oceans: More than 5 Trillion Plastic Pieces Weighing over 250,000 Tons Afloat at Sea. Plos One 9.

Eriksen, M., S. Mason, S. Wilson, C. Box, A. Zellers, W. Edwards, H. Farley, and S. Amato. 2013. Microplastic pollution in the surface waters of the Laurentian Great Lakes. Marine Pollution Bulletin 77:177-182.

Erni-Cassola, G., M. I. Gibson, R. C. Thompson, and J. A. Christie-Oleza. 2017. Lost, but Found with Nile Red: A Novel Method for Detecting and Quantifying Small Microplastics (1 mm to $20 \mathrm{mu}$ m) in Environmental Samples. Environmental Science \& Technology 51:13641-13648.

Faure, F., C. Saini, G. Potter, F. Galgani, L. F. de Alencastro, and P. Hagmann. 2015. An evaluation of surface micro- and mesoplastic pollution in pelagic ecosystems of the Western Mediterranean Sea. Environmental Science and Pollution Research 22:12190-12197.

Fazey, F. M. C., and P. G. Ryan. 2016a. Biofouling on buoyant marine plastics: An experimental study into the effect of size on surface longevity. Environmental Pollution 210:354-360.

Fazey, F. M. C., and P. G. Ryan. 2016b. Debris size and buoyancy influence the dispersal distance of stranded litter. Marine Pollution Bulletin 110:371-377.

Fisner, M., A. P. Majer, D. Balthazar-Silva, D. Gorman, and A. Turra. 2017. Quantifying microplastic pollution on sandy beaches: the conundrum of large sample variability and spatial heterogeneity. Environmental Science and Pollution Research 24:1373213740.

Frere, L., I. Paul-Pont, J. Moreau, P. Soudant, C. Lambert, A. Huvet, and E. Rinnert. 2016. A semi-automated Raman micro-spectroscopy method for morphological and chemical characterizations of microplastic litter. Marine Pollution Bulletin 113:461-468.

Galgani, F., T. Burgeot, G. Bocquene, F. Vincent, J. P. Leaute, J. Labastie, A. Forest, and R. Guichet. 1995. Distribution and Abundance of Debris on the Continental-Shelf of the Bay of Biscay and in Seine Bay. Marine Pollution Bulletin 30:58-62.

Galgani, F., D. Fleet, J. Van Franeker, S. Katsanevakis, T. Maes, J. Mouat, L. Oosterbaan, I. Poitou, G. Hanke, R. Thompson, E. Amato, A. Birkun, and C. Janssen. 2010. Marine Strategy Framework Directive, Task Group 10 Report: Marine Litter. European Comission Joint Research Centre, Ispra.

Galgani, F., J. P. Leaute, P. Moguedet, A. Souplet, Y. Verin, A. Carpentier, H. Goraguer, D. Latrouite, B. Andral, Y. Cadiou, J. C. Mahe, J. C. Poulard, and P. Nerisson. 2000. Litter on the sea floor along European coasts. Marine Pollution Bulletin 40:516-527.

Gall, S. C., and R. C. Thompson. 2015. The impact of debris on marine life. Marine Pollution Bulletin 92:170-179.

GESAMP. 2015. Sources, fate and effects of microplastics in the marine environment: a global assessment. IMO/FAO/UNESCOIOC/UNIDO/WMO/IAEA/UN/UNEP/UNDP Joint Group of Experts on

the Scientific Aspects of Marine Environmental Protection.

GESAMP. 2016. Sources, fate and effects of microplastics in the marine environment - part two of a global assessment.

Geyer, R., J. R. Jambeck, and K. L. Law. 2017. Production, use, and fate of all plastics ever made. Science Advances 3. 
GoScience. 2017. Future of the Sea:Plastic Pollution. Government Office for Science, London

Green, D. S. 2016. Effects of microplastics on European flat oysters, Ostrea edulis and their associated benthic communities. Environmental Pollution 216:95-103.

Green, D. S., B. Boots, D. J. Blockley, C. Rocha, and R. Thompson. 2015. Impacts of Discarded Plastic Bags on Marine Assemblages and Ecosystem Functioning. Environmental Science \& Technology 49:5380-5389.

Green, D. S., B. Boots, N. O'Connor, and R. C. Thompson. 2017. Microplastics affect the ecological functioning of an important biogenic habitat. Environmental Science and Technology 51:68-77.

Gregory, M. R. 2009. Environmental implications of plastic debris in marine settings entanglement, ingestion, smothering, hangers-on, hitch-hiking, and alien invasions. Philosophical transactions of the Royal Society B 364:2013-2026.

Gregory, M. R., and A. L. Andrady. 2003. Plastics in the marine environemnt. Pages 379-397 in A. L. Andrady, editor. Plastics and the environemnt. John Wiley and Sons, New Jersey.

Hidalgo-Ruz, V., L. Gutow, R. C. Thompson, and M. Thiel. 2012. Microplastics in the Marine Environment: A Review of the Methods Used for Identification and Quantification. Environmental Science \& Technology 46:3060-3075.

Holmes, L. A., A. Turner, and R. C. Thompson. 2012. Adsorption of trace metals to plastic resin pellets in the marine environment. Environmental Pollution 160:42-48.

Hopewell, J., R. Dvorak, and E. Kosior. 2009. Plastics recycling: challenges and opportunities. Philosophical transactions of the Royal Society B 364:2115-2126.

Jambeck, J. R., R. Geyer, C. Wilcox, T. R. Siegler, M. Perryman, A. Andrady, R. Narayan, and K. L. Law. 2015. Plastic waste inputs from land into the ocean. Science 347:768771.

Kamachi, M., Y. Ishikawa, H. Kawamura, N. Maximenko, J. Hafner, A. MacFadyen, and Ieee. 2016. Modeling the Drift of Japan Tsunami Marine Debris (JTMD) An application of High Computing Simulation and Data Assimilation.

Keswani, A., D. M. Oliver, T. Gutierrez, and R. S. Quilliam. 2016. Microbial hitchhikers on marine plastic debris: Human exposure risks at bathing waters and beach environments. Marine Environmental Research 118:10-19.

Kirstein, I. V., S. Kirmizi, A. Wichels, A. Garin-Fernandez, R. Erler, M. Loder, and G. Gerdts. 2016. Dangerous hitchhikers? Evidence for potentially pathogenic Vibrio spp. on microplastic particles. Marine Environmental Research 120:1-8.

Klein, S., E. Worch, and T. P. Knepper. 2015. Occurrence and Spatial Distribution of Microplastics in River Shore Sediments of the Rhine-Main Area in Germany. Environmental Science \& Technology 49:6070-6076.

Koelmans, A. A., E. Besseling, and W. J. Shim. 2016. Nanoplastics in the Aquatic Environment Critical Review. Pages 325-341 in M. bergman, L. Gutow, and M. Klages, editors. Marine Anthropogenic Litter. Springer, Heidelberg.

Koelmans, A. A., E. Besseling, A. Wegner, and E. M. Foekema. 2013. Plastic as a carrier of POPs to aquatic organisms: A model analysis. Environmental Sciecne and Technology 47:7812-7820.

Koelmans, A. A., T. Gouin, R. C. Thompson, N. Wallace, and C. Arthur. 2014. Plastics in the marine environment. Environmental Toxicology and Chemistry 33:5-10.

Kuhn, E. L., R. Bravo, and J. A. Fvan Franeker. 2015. Deleterious effects of litter on marine life. Pages 75-116 in M. bergman, L. Gutow, and M. Klages, editors. Marine Anthropogenic Litter. Springer, Heidelberg. 
Kukulka, T., G. Proskurowski, S. Moret-Ferguson, D. W. Meyer, and K. L. Law. 2012. The effect of wind mixing on the vertical distribution of buoyant plastic debris. Geophysical Research Letters 39.

Laist, D. W. 1997. Impacts of marine debris: entanglement of marine life in marine debris including a comprehensive list of species with entanglement and ingestion records. Pages 99-141 in J. M. Coe and B. D. Rogers, editors. Marine Debris: sources, impacts and solutions. Springer, Berlin.

Lattin, G. L., C. J. Moore, A. F. Zellers, S. L. Moore, and S. B. Weisberg. 2004. A comparison of neustonic plastic and zooplankton at different depths near the southern California shore. Marine Pollution Bulletin 49:291-294.

Lavers, J. L., and A. L. Bond. 2016. Selectivity of flesh-footed shearwaters for plastic colour: Evidence for differential provisioning in adults and fledglings. Marine Environmental Research 113:1-6.

Law, K. L., and R. Annual. 2017. Plastics in the Marine Environment. Pages 205-229 Annual Review of Marine Sciences, Vol 9.

Law, K. L., S. Moret-Ferguson, N. A. Maximenko, G. Proskurowski, E. E. Peacock, J. Hafner, and C. M. Reddy. 2010. Plastic Accumulation in the North Atlantic Subtropical Gyre. Science 329:1185-1188.

Law, K. L., and R. C. Thompson. 2014. Microplastics in the seas. Science 345:144-145.

Lebreton, L. C. M., and J. C. Borrero. 2013. Modeling the transport and accumulation floating debris generated by the 11 March 2011 Tohoku tsunami. Marine Pollution Bulletin 66:53-58.

Lebreton, L. C. M., J. Van der Zwet, J. W. Damsteeg, B. Slat, A. Andrady, and J. Reisser. 2017. River plastic emissions to the world's oceans. Nature Communications 8.

Lenz, R., K. Enders, and T. G. Nielsen. 2016. Microplastic exposure studies should be environmentally realistic. Proceedings of the National Academy of Sciences of the United States of America 113:E4121-E4122.

Lusher, A. L., M. McHugh, and R. C. Thompson. 2013. Occurrence of microplastics in the gastrointestinal tract of pelagic and demersal fish from the English Channel. Marine Pollution Bulletin 67:94-99.

Maes, T., R. Jessop, N. Wellner, K. Haupt, and A. G. Mayes. 2017. A rapid-screening approach to detect and quantify microplastics based on fluorescent tagging with Nile Red. Scientific Reports 7.

Mani, T., A. Hauk, U. Walter, and P. Burkhardt-Holm. 2015. Microplastics profile along the Rhine River. Scientific Reports 5.

Mato, Y., T. Isobe, H. Takada, H. Kanehiro, C. Ohtake, and T. Kaminuma. 2001. Plastic resin pellets as a transport medium for toxic chemicals in the marine environment. Environmental Science \& Technology 35:318-324.

Moser, M. L., and D. S. Lee. 1992. A 14-YEAR SURVEY OF PLASTIC INGESTION BY WESTERN NORTH-ATLANTIC SEABIRDS. Colonial Waterbirds 15:83-94.

MSFD GES Technical Subgroup on Marine Litter. 2011. Marine Litter Technical Recommendations for the Implementation of MSFD Requirements. Joint Research Centre - Institute for Environment and Sustainability, Luxembourg:.

Murphy, F., C. Ewins, F. Carbonnier, and B. Quinn. 2016. Wastewater Treatment Works (WwTW) as a Source of Microplastics in the Aquatic Environment. Environmental Science \& Technology 50:5800-5808.

Napper, I. E., A. Bakir, S. J. Rowland, and R. C. Thompson. 2015. Characterisation, Quantity and Sorptive Properties of Microplastics Extracted From Cosmetics. Marine Pollution Bulletin 99:178-185. 
Napper, I. E., and R. C. Thompson. 2016. Release of synthetic microplastic plastic fibres from domestic washing machines: Effects of fabric type and washing conditions. Marine Pollution Bulletin 112:39-45.

Nelms, S. E., C. Coombes, L. C. Foster, T. S. Galloway, B. J. Godley, P. K. Lindeque, and M. J. Witt. 2017. Marine anthropogenic litter on British beaches: A 10-year nationwide assessment using citizen science data. Science of the Total Environment 579:1399-1409.

Obbard, R. W., S. Sadri, Y. QiWong, A. A. Khitun, I. Baker, and R. C. Thompson. 2014. Global warming releases microplastic legacy frozen in Arctic Sea ice. Earth's Future 2:315-320.

Oehlmann, J., U. Schulte-Oehlmann, W. Kloas, O. Jagnytsch, I. Lutz, K. O. Kusk, L. Wollenberger, E. M. Santos, G. C. Paull, K. J. W. Van Look, and C. R. Tyler. 2009. A critical analysis of the biological impacts of plasticizers on wildlife. Philosophical transactions of the Royal Society B 364:2047-2062.

Pahl, S., and K. J. Wyles. 2017. The human dimension: how social and behavioural research methods can help address microplastics in the environment. Analytical Methods 9:1404-1411.

Pahl, S., K. J. Wyles, and R. C. Thompson. 2017. Channelling passion for the ocean toward plastic pollution. Nature Human Behaviour 1:697-699.

Parsons, G., A. Morgan, J. Whitehead, and T. Haab. 2006. The Welfare Effects of PfiesteriaRelated Fish Kills: A Contingent Behavior Analysis of Seafood Consumers. Agricultural and Resource Economics Review, 35:348-356.

Plastics Europe. 2015. Plastics the facts 2015 An analysis of European plastics production, demand and waste data. Plastics Europe, Brussels.

Ribic, C. A., S. B. Sheavly, D. J. Rugg, and E. S. Erdmann. 2010. Trends and drivers of marine debris on the Atlantic coast of the United States 1997-2007. Marine Pollution Bulletin 60:1231-1242.

Rillig, M. C. 2012. Microplastic in Terrestrial Ecosystems and the Soil? Environmental Science \& Technology 46:6453-6454.

Rochman, C. M., and M. A. Browne. 2013. Classify plastic waste as hazardous. Nature 494:169-171.

Rochman, C. M., E. Hoh, T. Kurobe, and S. J. Teh. 2013. Ingested plastic transfers hazardous chemicals to fish and induces hepatic stress. Nature Scientific Reports 3:3263.

Roy, P. K., M. Hakkarainen, I. K. Varma, and A. Albertsson. 2011. Degradable Polyethylene: Fantasy or Reality. Environmental Sciecne and Technology:4217-4227.

Ryan, P. G. 2015. Does size and buoyancy affect the long-distance transport of floating debris? Environmental Research Letters 10.

Ryan, P. G., C. J. Moore, J. A. van Franeker, and C. L. Moloney. 2009. Monitoring the abundance of plastic debris in the marine environment. Philosophical transactions of the Royal Society B 364:1999-2012.

Santos, R. G., R. Andrades, L. M. Fardim, and A. S. Martins. 2016. Marine debris ingestion and Thayer's law - The importance of plastic color. Environmental Pollution 214:585588.

Schmidt, C., T. Krauth, and S. Wagner. 2017. Export of Plastic Debris by Rivers into the Sea. Environmental Science \& Technology 51:12246-12253.

Sussarellu, R., M. Suquet, Y. Thomas, C. Lambert, C. Fabioux, M. E. J. Pernet, N. Le Goic, V. Quillien, C. Mingant, Y. Epelboin, C. Corporeau, J. Guyomarch, J. Robbens, I. Paul-Pont, P. Soudant, and A. Huvet. 2016. Oyster reproduction is affected by exposure to polystyrene microplastics. Proceedings of the National Academy of Sciences of the United States of America 113:2430-2435. 
Sutherland, W. J., M. Clout, I. M. Cote, P. Daszak, M. H. Depledge, L. Fellman, E. Fleishman, R. Garthwaite, D. W. Gibbons, J. De Lurio, A. J. Impey, F. Lickorish, D. Lindenmayer, J. Madgwick, C. Margerison, T. Maynard, L. S. Peck, J. Pretty, S. Prior, K. H. Redford, J. P. W. Scharlemann, M. Spalding, and A. R. Watkinson. 2010. A horizon scan of global conservation issues for 2010. Trends in Ecology \& Evolution 25:1-7.

Tagg, A. S., J. P. Harrison, Y. Ju-Nam, M. Sapp, E. L. Bradley, C. J. Sinclair, and J. J. Ojeda. 2017. Fenton's reagent for the rapid and efficient isolation of microplastics from wastewater. Chemical Communications 53:372-375.

Tanaka, K., H. Takada, R. Yamashita, K. Mizukawa, M. Fukuwaka, and Y. Watanuki. 2013. Accumulation of plastic-derived chemicals in tissues of seabirds ingesting marine plastics. Marine Pollution Bulletin 69:219-222.

Teuten, E. L., J. M. Saquing, D. R. U. Knappe, M. A. Barlaz, S. Jonsson, A. Björn, S. J. Rowland, R. C. Thompson, T. S. Galloway, R. Yamashita, D. Ochi, Y. Watanuki, C. Moore, P. Viet, T. S. Tana, M. Prudente, R. Boonyatumanond, M. P. Zakaria, K. Akkhavong, Y. Ogata, H. Hirai, S. Iwasa, K. Mizukawa, Y. Hagino, A. Imamura, M. Saha, and S. Takada. 2009. Transport and release of chemicals from plastics to the environment and to wildlife. Philosophical transactions of the Royal Society B 364:2027-2045.

Thomas, G. O., W. Poortinga, and E. Sautkina. 2016. The Welsh Single-Use Carrier Bag Charge and behavioural spillover. Journal of Environmental Psychology 47:126-135.

Thompson, R., C. Moore, A. Andrady, M. Gregory, H. Takada, and S. Weisberg. 2005. New directions in plastic debris. Science 310:1117-1117.

Thompson, R. C. 2015. Microplastics in the marine environment sources, consequences and solutions. Pages 185-200 in M. Bergman, L. Gutow, and M. LKlages, editors. Marine Anthropogenic Litter. Springer, Heidelberg.

Thompson, R. C., C. Moore, F. S. vom Saal, and S. H. Swan. 2009a. Plastics, the environment and human health: current consensus and future trends. Philosophical transactions of the Royal Society B 364:2153-2166.

Thompson, R. C., Y. Olsen, R. P. Mitchell, A. Davis, S. J. Rowland, A. W. G. John, D. McGonigle, and A. E. Russell. 2004. Lost at sea: Where is all the plastic? Science 304:838-838.

Thompson, R. C., S. H. Swan, C. Moore, and F. S. vom Saal. 2009b. Our Plastic Age Philosophical transactions of the Royal Society B 364:1973-1976.

Unger, B., E. L. B. Rebolledo, R. Deaville, A. Grone, L. L. Ijsseldijk, M. F. Leopold, U. Siebert, J. Spitz, P. Wohlsein, and H. Herr. 2016. Large amounts of marine debris found in sperm whales stranded along the North Sea coast in early 2016. Marine Pollution Bulletin 112:134-141.

Van Cauwenberghe, L., and C. R. Janssen. 2014. Microplastics in bivalves cultured for human consumption. Environmental Pollution 193:65-70.

Van Cauwenberghe, L., A. Vanreusel, J. Mees, and C. R. Janssen. 2013. Microplastic pollution in deep-sea sediments. Environmental pollution (Barking, Essex : 1987) 182:495-499.

Van Franeker, J., E. L. Kuhn, and R. Bravo. 2016. Fulmar Litter EcoQO monitoring in the Netherlands - Update 2015 Wageningen Marine Research.

van Sebille, E., C. Wilcox, L. Lebreton, N. Maximenko, B. D. Hardesty, J. A. van Franeker, M. Eriksen, D. Siegel, F. Galgani, and K. L. Law. 2015. A global inventory of small floating plastic debris. Environmental Research Letters 10. 
van Wezel, A., I. Caris, and S. A. E. Kools. 2016. Release of primary microplastics from consumer products to wastewater in the Netherlands. Environmental Toxicology and Chemistry 35:1627-1631.

Watts, A. J. R., M. A. Urbina, S. Corr, C. Lewis, and T. S. Galloway. 2015. Ingestion of Plastic Microfibers by the Crab Carcinus maenas and Its Effect on Food Consumption and Energy Balance. Environmental Science \& Technology 49:14597-14604.

Werner, S., A. Budziak, J. van Franeker, F. Galgani, G. Hanke, T. Maes, M. Matiddi, P. Nilsson, L. Oosterbaan, E. Priestland, R. Thompson, J. Veiga, and T. Vlachogianni. 2016. Harm caused by Marine Litter. MSFD GES TG Marine Litter - Thematic Report.

Wilcox, C., B. D. Hardesty, R. Sharples, D. A. Griffin, T. J. Lawson, and R. Gunn. 2013. Ghostnet impacts on globally threatened turtles, a spatial risk analysis for northern Australia. Conservation Letters 6:247-254.

Woodall, L. C., A. Sanchez-Vidal, M. Canals, G. L. J. Paterson, R. Coppock, V. Sleight, A. Calafat, A. D. Rogers, B. E. Narayanaswamy, and R. C. Thompson. 2014. The deep sea is a major sink for microplastic debris. Royal Society Open Science 1:140317.

Wright, S. L., D. Rowe, R. C. Thompson, and T. S. Galloway. 2013a. Microplastic ingestion decreases energy reserves in marine worms. Current Biology 23:1031-1033.

Wright, S. L., R. C. Thompson, and T. S. Galloway. 2013b. The physical impacts of microplastics on marine organisms: A review. Environmental Pollution 178:483-492.

Xanthos, D., and T. R. Walker. 2017. International policies to reduce plastic marine pollution from single-use plastics (plastic bags and microbeads): A review. Marine Pollution Bulletin 118:17-26.

Zettler, E. R., T. J. Mincer, and L. A. Amaral-Zettler. 2013. Life in the "Plastisphere": Microbial Communities on Plastic Marine Debris. Environmental Science \& Technology 47:7137-7146.

Zitko, V., and M. Hanlon. 1991. Another Source of Pollution By Plastics - Skin Cleaners With Plastic Scrubbers. Marine Pollution Bulletin 22:41-42. 